\title{
El sistema cannabinoide como diana terapéutica
}

\author{
Miguel Navarro García \\ Catedrático de Psicofarmacología. Departamento de Psicología. Instituto Complutense de Drogodependencia. \\ Facultad de Psicología. Universidad Complutense de Madrid. \\ Enviar correspondencia a: \\ Miguel Navarro. mnavarro@psi.ucm.es.
}

\section{RESUMEN:}

Se pretende realizar un comentario sobre el uso potencial de fármacos que modulan el sistema endocannabinoide.

A partir de 1988 cuando se evidenció el primer receptor cannabinoide en el cerebro $\left(\mathrm{CB}_{1}\right)$ y cuatro años más tarde el primer ligando endógeno que interaccionaba ese receptor (anandamida), se demostró un sistema de señalización celular en el cerebro que posteriormente se extendió a lo largo del organismo.

El desarrollo de nuevos fármacos cannabinoides se han sumado a los ya conocidos, que permiten un mayor conocimiento en la síntesis, liberación, recaptación y degradación de los ligandos endocannabinoides y un mayor y más extenso conocimiento sobre nuevas estrategias para la remisión o el tratamiento de múltiples enfermedades, entre las que se incluyen la psicosis, trastornos motores asociados a varias enfermedades neuropsiquiátricas (Parkinson, Huntington, Gilles de la Tourette, coreas, etc.), trastornos alimentarios, trastornos adictivos, dolor o enfermedades neoplásicas.

La vieja pretensión social de la utilización de la marihuana como medicamento de amplios efectos farmacológicos, ha dado paso al creciente y expansivo campo científico del sistema endocannabinoide. Sin embargo, la utilización terapéutica de los cannabinoides no está exenta de polémica, especialmente a lo que se refiere al uso de la planta, sus posibles consecuencias y las perspectivas futuras que representa el sistema endocannabinoide como una diana farmacológica por su potencial uso terapéutico y papel que interpreta en la fisiología general.

Palabras clave: Asistema cannabinoide, potencial terapéutico, marihuana.

\section{ABSTRACT:}

The aim is to raise a commentary on the potential use of drugs that modulate the endocannabinoid system.

The discovery in 1988 of a brain cannabinoid receptor $\left(C_{1}\right)$ and four years later of the first endogenous ligand for that receptor, anandamide, demonstrated the existence in the brain of an endogenous cannabinoid signalin system later spread along the organism.

The recent development of new drugs such as those aimed to interact with either the $\mathrm{CB}_{1}$ or the mechanisms involved on the release, uptake and degradation of endogenous cannabinoids will help to develop new strategies for the treatment of psychiatric and neurological disorders. They include the psychosis, motor disorders associated with several neuropsychiatric diseases (Parkinson, Huntington, Gilles de la Tourette, corea, etc.), food disorders, addictive disorders, pain or cancer diseases.

The old social claim of using marijuana as a medicine has now become increasing an expansive a very active scientific field of the endocannabinoid system. Nevertheless, the therapeutic utilization of the cannabinoid is not exempt from polemic, specially to the use of the plant and the possible consequences and the future perspectives that the endocannabinoid system represents endocannabinoide a pharmacological target ant its potential therapeutic use and a role the general physiology.

Key words: Cannabinoid system, therapeutic potential, marijuana.

\section{INTRODUCCIÓN}

$\mathbf{L}$ a utilización clínica de la planta cannabis sativa como fuente de remedios terapéuticos tienen su origen en la medicina oriental de China y la India.
El uso como medicamento se refleja en el compendio chino de hierbas medicinales, el Pen ts'ao, publicado por primera vez en torno al año 2800 a.C, en el que se recomendaba esta droga para tratar el estreñimiento, la gota, la malaria, el reumatismo entre otras indicaciones, y siglos más tarde aún seguían recogiéndose en los 
textos medicinales chinos los preparados de cannabis, por sus propiedades analgésicas, en las intervenciones quirúrgicas (Robinson, 1996). En la medicina hindú, el uso del cannabis tiene la misma tradición que en China, como lo atestigua el tratado médico hindú más antiguo, el Athera Vera (2000-1400 a. C.), en el que se menciona como bhang (la denominación con la se conoce la marihuana en la India) (Iversen, 2001).

Sin embargo, las preparaciones del cannabis tuvieron una pobre penetración en los países occidentales hasta el s. XIX. Como puede observarse alguna referencia en el libro Materia Medica de Dioscórides o por alguna mención de Andrés Laguna (médico de Felipe II), quien exclusivamente incluyó como posible aplicación terapéutica del cannabis en la inflamación y en los dolores locales.

Durante el mencionado siglo se intentó aislar infructuosamente sus principios activos, llegándose a algunas conclusiones interesantes, como fue la falta de letalidad de las preparaciones de cannabis y la gran variabilidad observada en la potencia farmacológica cuando se administran preparaciones de la planta (Dewey, 1986).

Un hecho muy perjudicial para la investigación con los principios activos de la planta y para su posible utilización terapéutica, lo representó la ley americana que prohibió su utilización (Marijuana Tax Act en 1937), incluyéndola en la clase I de las drogas narcóticas (la más restrictiva). Esto también significó un freno importante en la utilización recreacional de las diversas formas de consumo de la planta en la mayor parte de los países, aunque lejos de paralizar dicho consumo, continúa su consumo y actualmente sigue siendo la droga de abuso más utilizada en el mundo, después del alcohol y el tabaco y sigue elevándose el consumo.

Las bases farmacológicas de los efectos terapéuticos del cannabis comienzan desde que en 1964 Gaoni y Mechoulam aislan y sintetizan el principal principio psicoactivo de la planta, (-)- $\Delta^{9}$-tetrahidrocannabinol (THC). Desde entonces hasta ahora, y en particular, a partir de la pasada década, se ha producido una rápida difusión y una enorme expansión en el conocimiento del papel que interpretan los cannabinoides y sus respectivos receptores en la fisiología.

El desarrollo de nuevos cannabinoides ha propiciado el descubrimiento del sistema cannabinoide endógeno, también denominado endocannabinoide, identificado en el Sistema Nervioso Central (SNC), y también se encontró una señalización similar en el tejido periférico (Munro et al., 1993). El sistema endocannabinoide periférico participa en funciones fisiológicas importantes como en la regulación cardiovascular (Mechoulam et al., 1998) con una contribución relevante en el shock hemorrágico (Wagner et al., 1997), en la regulación del sistema inmune (Klein et al., 1998) en el control de la presión intraocular (Porcella et al., 1998), o en la iniciación de la respuesta al dolor (Calignano et al, 1998).

Desde el punto de vista celular, los cannabinoides psicoactivos afectan la liberación y la recaptación de neurotransmisores y modulan los mecanismos de transducción, sobre todo porque disminuyen principalmente la producción de AMPc y la conductancia al $\mathrm{Ca}^{++}$y K+ (Dewey, 1986, Navarro y Rodríguez de Fonseca, 1998).

\section{CANNABINOIDES NATURALES Y SINTÉTICOS}

El aislamiento de los principales constituyentes del cannabis, denominados cannabinoides, ejerció una nueva era en su estudio y en sus potenciales aplicaciones terapéuticas (Gaoni y Mechoulam, 1964). Alguno son psicoactivos, siendo el principal el THC y otros no psicoactivos como el cannabidiol que es el más abundante en la planta.

A diferencia del resto de las drogas de abuso que son ácidos o álcalis, el THC carece de estas propiedades, por lo que no puede cristalizarse; es decir, los cannabinoides naturales son lípidos, insolubles en agua, y pasan fácilmente por las membranas, incluída la barrera hematoencefálica, aunque presentan dificultades para la administración endovenosa. Se acumulan en el tejido graso y una vez que va disminuyendo la concentración plasmática, se invierte su distribución (redistribución), y vuelven al torrente sanguíneo a partir de los depósitos grasos, por lo cual no disminuye bruscamente su concentración plasmática a diferencia del resto de drogas de abuso y probablemente sea la causa principal de no presentar un síndrome de abstinencia tan marcado como sucede con otras drogas de abuso una vez que se dejan de consumir (Dewey, 1986).

La administración del THC en modelos animales produce un perfil farmacológico característico, que incluye: analgesia, hipotermia, inmovilidad (disminución de la actividad motora) y catalepsia. Esta tétrada farmacológica se considera clásica para identificar compuestos cannabinoides (Abood y Martín, 1992).

Sin embargo, en los humanos se han puesto de manifiesto un mayor número de efectos farmacológicos que en los animales y de forma más explícita, son el caso de la hipotensión. Capítulo aparte merece el papel que interpreta el receptor CB1 en la disminución de la liberación pulsátil de las gonadotrofinas y hormona de crecimiento, unido a la función inhibitoria de estos compuestos sobre la liberación de prolactina y TSH, así como la activación ejercida sobre el eje hipotálamo-hipófiso-adrenal, todo ello indica la nueva función del sistema endocannábico en la regulación del sistema reproductor, de la lactación, el metabolismo, la respuesta al afrontamiento del estrés y la interven- 
ción en la respuesta inmunitaria (Dewey, 1986). Los cannabinoides disminuyen la sensación de la náusea y el vómito, la motilidad intestinal, disminuye la presión intraocular, la coordinación motora, la percepción visual, modifica las conductas alimentaria y altera la memoria a corto plazo. La administración de THC produce relajación o ansiedad según sea la dosis baja o alta respectivamente y también interviene en sus efectos la influencia del entorno que pueda ser más o menos familiar (Rodríguez de Fonseca et al, 1996). Por lo tanto, los cannabinoides son unos compuestos con gran variedad de efectos farmacológicos que explica la profusión y extensión de sus ligandos endógenos y receptores por la totalidad del organismo y abre inmensas expectativas científicas.

\section{CRITERIOS DE DEPENDENCIA DEL CONSUMO DE CANNABIS/CANNABINOIDES}

Al igual que como sucede con las otras drogas de abuso, el cannabis modifica el procesamiento del refuerzo positivo o de la recompensa (Navarro y Rodríguez de Fonseca, 1998; Gardner y Borrel, 1998). Las preparaciones de la cannabis sativa sigue siendo la droga ilegal más consumidas del mundo. Y por ello, las propiedades reforzantes de los cannabinoides psicoactivos continúan siendo motivo de debate científico y social. La activación del receptor CB1 inducida por los cannabinoides psicoactivos no sólo producen la activación del sistema de recompensa en los diferentes modelos animales (Navarro et al., 2001; Maldonado, 2002), sino que claramente muestran un perfil farmacológico muy similar a otras drogas de abuso como el etanol o los opioides en el síndrome de abstinencia inducido por sus correspondientes antagonistas o con antagonistas cruzados como los opioides y cannabinoides (Rodríguez de Fonseca et al., 1997). Sin embargo, en los citados modelos animales cuando el síndrome de abstinencia es espontáneo; es decir, no inducido por antagonistas, solamente hay evidencias de signos de abstinencia con los cannabinoides más potentes como el CP ó el WIN, pero no ocurre lo mismo con el THC.

En este sentido, en el ratón puede evidenciarse signos de abstinencia comportamentales y neuroadaptativos tras el cese de la administración de un potente agonista del receptor CB1, CP-55,940, que incluyen una marcada alteración de signos motores característicos del síndrome de abstinencia a cannabinoides y una regulación al alza de la expresión genética del receptor CB1 en áreas cerebrales importantes en la expresión comportamental de adicción (Oliva et al., 2004), también el síndrome de abstinencia espontáneo aparece en la rata tras la interrupción de una infusión continua de otro potente agonista del receptor CB1, WIN-55212-2 (Aceto et al., 2001), algo similar sucede tras el cese de la administración exógena en ratas del propio ligando endógeno: anandamida (Costa et al., 2000). Sin embargo, esos signos de abstinencia espontánea no se aprecian tras el cese de la administración crónica con THC (Diana et al., 1998), aunque es probable que sean debidas a causas farmacocinéticas por las que el THC no provoca un síndrome de abstinencia espontáneo en el animal y no a otros motivos (Aceto et al., 2001).

Por el contrario, en el humano sí hay un síndrome de abstinencia espontáneo después de la interrupción tras la exposición crónica a cannabis o en sus múltiples formas de preparaciones y rutas de administración del THC, como lo avalan numerosos datos experimentales (Haney et al., 1999(a), 1999(b), 2001 y 2004) .

Aunque, es preciso indicar dos aspectos importantes a este respecto; en primer lugar, ¿la sintomatología de abstinencia por la administración de cannabinoides/ cannabis en el humano es lo suficientemente importante como para frenar cualquier estudio que logre conclusiones sobre su potencialidad terapéutica?. La mayor parte de los estudios, indican que el citado síndrome se manifiesta por irritabilidad, ansiedad, sensaciones desagradables, problemas en la conciliación del sueño, escalofrío y deseo compulsivo (craving) de consumir la droga, aunque todos ellos son de moderada intensidad (Herning et al., 2003 y Haney et al., 2004). Estudios clínicos y epidemiológicos que indican que el fenómeno de abstinencia es relativamente común y asociado con problemas psicosociales significativos y varios de los citados estudios han demostrado que el síndrome de abstinencia es relativamente común entre jóvenes consumidores (heavys) que demandan intervención terapéutica en la mayoría de ellos, habiéndose duplicado el número de demandas en los últimos 10 años (Budney y Moore, 2002).

Y en segundo lugar, la adicción presente en el consumo recreacional de la droga parece baja, según se desprende de un informe del Institute of Medicine en 1999, en el que se indicó que sólo el 9\% de todos los individuos que habían probado la droga cumplían criterios de adicción establecidos por el DSM IV (compendio que recoge signos/síntomas de las principales enfermedades psiquiátricas), dato marcadamente inferior al producido por el alcohol (15\%), cocaína (17\%), heroína (23\%) y tabaco (32\%).

Aunque, son necesarios más estudios para poder alcanzar un criterio firme de la importancia de estos síntomas en sujetos con problemas psiquiátricos asociados, argumentos parecidos han dado lugar en tiempos pasados, especialmente en nuestro país, tratamientos inadecuados con los derivados del opio, especialmente la morfina, privando del beneficio de su utilización a muchos pacientes con dolor, cuando en la actualidad sabemos que la adicción por la utilización terapéutica de este fármaco es prácticamente despreciable cuando se realiza con el adecuado control sanitario (Iversen, 2001). 


\section{ADMINISTRACIÓN DE LOS CANNABINOIDES}

¿Debe recomendarse el uso terapéutico de la marihuana/hashish o los cannabinoides naturales/sintéticos? La idea de quemar o inhalar los compuestos resultantes de la combustión de hojas secas o resina de la planta, está muy bien documentada la presencia de 60 diferentes principios activos que por la combustión se transforman en más de 400 compuestos (un porro es un laboratorio químico en miniatura), algunos de los cuales se sabe de su capacidad tóxica y cancerígena que son la base de bronquitis crónica y cáncer de pulmón que provoca el consumo de la planta fumada (British Medical Association, 1997); por lo cual, esta forma de administración no parece la manera ideal de recomendar el consumo y desde luego dista de ser la forma más aceptada en el proceso habitual de recomendar la aprobación de un medicamento, cuyos objetivos son la purificación, la precisa cuantificación de la dosis y la reproductibilidad de los resultados. Parece obvio que estos argumentos deberían ser más debatidos por aquellos profesionales que optan por recomendar la utilización de la planta. Sin embargo, hay que tener en cuenta que la ingestión oral de THC, bien en extracto de cannabis o de los cannabinoides sintéticos dronabinol (Marinol) o nabilona (Cesamet) tienen serios problemas farmacocinéticos que impide su administración endovenosa y el retardo en el comienzo de los efectos psicoactivos (pasados treinta a sesenta minutos) (Beal et al., 1995; Fabre et al., 1981).

A este respecto, parece que urgen estudios clínicos que evalúen la posible inhalación por calentamiento de la planta o desarrollar métodos alternativos antes de recomendar el consumo fumado de la marihuana/ hashish para tratamientos prolongados, planteándose solamente la vía fumada en tratamientos compasivos en fases terminales de enfermedades graves de duración previsiblemente corta (caquexia por SIDA o dolor por cáncer) en aquellos pacientes que demanden esa opción frente a otras alternativas fracasadas (Pacula et al., 2002).

\section{ACTUALIDAD Y PERSPECTIVA FUTURA DE LOS CANNABINOIDES COMO MEDICAMENTOS}

¿El uso antiemético de los cannabinoides se ha vuelto obsoleto ante el desarrollo de modernos psicofármacos?. Estudios clínicos citados anteriormente ponen de manifiesto que es posible obtener buenos resultados con fármacos derivados del cannabis, aunque, ni el dronabinol ni la nabilona han gozado de buena aceptación clínica. La dosis eficaz de cualquiera de ellos como antiemético se aproxima a los efectos sedantes e intoxicadores (Iversen, 2001). Sin embargo, en la última década existen toda una serie de antieméticos cada vez más potentes y eficaces en el control de la emesis temprana y tardía inducida por el tratamiento quimioterápico. Así los antagonistas del receptor $5 \mathrm{HT}_{3}$, ondansetron (Zofran), granisetron (Kytril), tropisetron (Navoban), (Dempsey et al., 2004) combinados con dexametasona controlan del 80-90\% de los pacientes, muy por encima del efecto obtenido con dronabinol (Schwartz et al., 1997), especialmente el palonosetron con el mismo mecanismo de acción y con muy escasos efectos indeseables (Siddiqui y Scott, 2004); por último, existe un nuevo potente antiemético antagonista del receptor $\mathrm{NK}_{1}$ de la neurokinina (Aprepitant), que parece muy eficaz para los casos resistentes a los antagonistas serotonérgicos y de baja toxicidad con la ventaja frente a los cannabinoides actuales de poder ser administrados oral o intravenosamente (Dando y Perry, 2004). No obstante, las dosis subterapéuticas (sin efectos subjetivos de intoxicación) de cannabinoides asociadas a los actuales antieméticos sería una opción que actualmente convendría estudiar.

A pesar de las constantes esperanzas de los potenciales usos terapéuticos de los cannabinoides hasta ahora, lamentablemente, no se ha conseguido obtener un efecto terapéutico primario para alguna enfermedad, salvo probablemente en el dolor neuropático en el que un potente análogo del THC (ácido 1',1'dimetilheptilDelta8-tetrahidrocannabinol-11-oico), denominado CT-3, especialmente indicado en la alodinia (alteraciones de la sensibilidad táctil en las que se asocia sensaciones dolorosas al frío), característica de los efectos indeseables de los citostáticos (como los derivados del platino) (Karst et al., 2003).

Sin embargo, los científicos estamos entusiasmados por el descubrimiento de este nuevo mecanismo modulador natural que representa el sistema endocannabinoide (Giuffrida et al., 1999) Es altamente probable que los dos tipos de receptores y ligandos endógenos identificados hasta ahora, sean el inicio de muchos descubrimientos que quedan por hacer.

Los numerosos cannabinoides que actúan farmacodinámicamente como agonistas, antagonistas y agonistas inversos del sistema endocannabinoide, colectivamente son una poderosa herramienta para la caracterización de receptores cannabinoides y la identificación de vías intrínsecas de señalización celular. Muchos de estos mecanismos de señalización celular activados por los cannabinoides son la consecuencia de estudios receptoriales expresados en celulas tumorales, el papel que interpretan los receptores cannabinoides en la biología celular tumoral es un campo apasionante y posiblemente en un futuro inmediato desarrollarán nuevos compuestos antitumorales (Howl, 2003).

Paralelamente, los efectos neuroprotectores de los cannabinoides, especialmente el dexanabinol (HU-211), está mostrando el sistema de señalización celular que protege la neurona de las consecuencias neurotóxicas en diversos modelos animales, como las generadas por 
la actividad alterada de las descargas responsables de las crisis epilépticas (Marsicano et al., 2003), la capacidad antioxidante en el SNC (Veldhuis et al., 2003) o de la participación del sistema endocannábico en la extinción de los recuerdos aversivos (Marsicano et al., 2002), o de la implicación del sistema cannabinoide en el control alimentario sin consecuencias centrales (Rodríguez de Fonseca et al., 2001; Gomez et al., 2002) por enumerar algunos aspectos de la ingente cantidad de nuevos logros que apunta la investigación sobre el sistema endocannabinoide y de los cannabinoides (Navarro et al., 2000).

No obstante, parece cada vez más probable la necesidad de una reclasificación por la DEA (Agencia americana antidroga para el cumplimiento de la ley) de la actual situación de los cannabinoides a la clase III (la menos restrictiva), haciéndola más asequible para reali- zar ensayos clínicos controlados, que son la única base real para el avance en el conocimiento de la capacidad de los cannabinoides como herramienta terapéutica.

Igualmente, sería deseable distinguir, en lo posible, los debates del consumo de la planta o las diversas preparaciones de la misma con fines recreacionales, que es un debate necesario para que la sociedad pueda pronunciarse con respecto del alcance de las normas de su utilización social como droga de abuso, del otro debate en los foros científicos y profesionales sanitarios sobre el estudio reglado de los cannabinoides como medicamento, que como otras sustancias tienen efectos beneficiosos e indeseables, dirigido al sistema endocannabinoide como diana terapéutica para paliar múltiples enfermedades, de las que cada vez parece que estamos más cerca de solucionar por esta vía. 
